\title{
As Influências da Liderança nos Ambientes Organizacionais
}

\author{
The Influences of Leadership in Organizational Environments
}

\author{
Osnei Francisco Alves
}

Universidad Nacional de Misiones, Programa de Pós-Graduação Stricto Sensu em Administração. Argentina. E-mail: consultorosnei@gmail.com

\begin{abstract}
Resumo
Preparar-se para os desafios com a mudança e alcançar seu melhor resultado requer o uso de ferramentas práticas e eficazes, que nos ajude na gestão, incentivo, coragem e a flexibilidade. Pois, insano é continuar a fazer o que sempre se fez, desejando conquistar resultados diferentes, assim o tema liderança possui uma grande influência histórica devido a sua trajetória em todas as bases de poder e gestão da sociedade. Apesar de ser algo muito debatido, os estilos de liderança e a forma entendimento tem muitas vertentes devido as raízes sociológicas e culturas que desafiam as mentalidades conceituais. O objetivo do artigo foi identificar em uma pesquisa de 352 pessoas na cidade de Curitiba-PR, com um questionário contendo 12 perguntas com características quantitativas e qualitativas. A pesquisa na sua grande maioria foi realizada com pessoas com ensino superior completo, assim foi possível constatar a relação da liderança com um público alvo que tem uma profissão consolidada e que já possuem um cargo de liderança, que almejam ou desenvolvem o papel de liderança ou tem contato com líderes. Na análise dos resultados observou-se o perfil do líder na visão das organizações na forma de hierarquia com os estágios: estratégico, tático e operacional e as suas relações, buscando identificar comportamentos da liderança com maior efetividade nas organizações. A conclusão do artigo foi relatar as considerações da liderança nas relações organizacionais e os perfis de líderes que estabelecem as maiores influências diante das metas organizacionais.
\end{abstract}

Palavras-chave: Influência. Liderança. Mudança. Perfil.

\begin{abstract}
Preparing for the challenges with change and achieving your best results requires the use of practical and effective tools that help us in management, encouragement, courage and flexibility. For it is insane to continue doing what has always been done, wishing to achieve different results, so the topic leadership has a great historical influence due to its trajectory in all bases of power and management of society. Despite being much debated, leadership styles and understanding form have many strands due to the sociological roots and cultures that challenge the conceptual mentalities. The objective of the article was to identify in a survey of 352 people in the city of Curitiba-PR, with a questionnaire containing 12 questions with quantitative and qualitative characteristics. The majority of the research was carried out with people with higher education, so it was possible to verify the relationship of leadership with a target audience that has a consolidated profession and that already hold a leadership position, that aim or develop the leadership role or has contact with leaders. In the analysis of the results, we observed the profile of the leader in the hierarchical organization of the hierarchy with the stages: strategic, tactical and operational and their relationships, seeking to identify leadership behaviors with greater effectiveness in organizations. The conclusion of the article was to report the considerations of leadership in organizational relationships and the profiles of leaders that establish the major influences in the face of organizational goals.
\end{abstract}

Keywords: Change. Influence. Leadership. Profile.

\section{Introdução}

Liderança, na concepção de Robbins e Judge (2014), é a capacidade de influenciar um grupo para a realização de uma determinada tarefa ou para o alcance de um conjunto de metas. Tal influência pode ser formal ou informal.

Líder é a pessoa no grupo que, formal ou informalmente, tem a responsabilidade de dirigir e coordenar as atividades relacionadas a uma determinada tarefa, sendo sua maior atenção destinada à conquista de algum objetivo do grupo. Estilo de liderança, por sua vez, é a maneira como uma pessoa com posição de líder influencia os demais membros do grupo (MOSCOVICI, 2013).

Ribeiro (2010) afirma que Kurt Lewin foi um psicólogo que muito contribuiu para o movimento das ciências do comportamento. Iniciou suas pesquisas a respeito de mudança de hábitos, de liderança e de comunicação. Lewin também conduziu experimentos de grupo para medir a atmosfera de liderança (democrática, autocrática, laissezfaire). Sua preocupação nos experimentos era encontrar soluções operacionais para a formação de líderes e de grupo democráticos.

Para complementar Ribeiro (2010) descreve Liderança Autocrática como modelo no qual a líder fixa as diretrizes, sem qualquer participação do grupo. É ele também quem estabelece, uma a uma e de modo imprevisível, as providencias e as técnicas necessárias para a execução de tarefas, além de determinar aquela que cada um deve executar e quem será o 
companheiro de trabalho.

$\mathrm{Na}$ Liderança democrática as diretrizes são debatidas e decididas pelo grupo, que é estimulado e assistido pelo líder.

Liderança Liberal (laissez-faire), é liberdade total para as decisões grupais ou individuais, com participação mínima do líder. A participação do líder no debate é pequena, limitandose, apenas, a apresentar os variados materiais à disposição do grupo para o cumprimento de suas funções, esclarecendo que pode fornecer informações desde que solicitadas.

A liderança situacional ou de contingência diz respeito ao contexto da dinâmica interpessoal, ou seja, se ocupa das situações ou contingências que envolvem o desenrolar das atividades ou ações de liderança (MOSCOVICI, 2013).

Os líderes influenciam as pessoas a fazer coisas através do uso do poder e da autoridade. O poder é a habilidade ou potencial de influenciar decisões e controlar recursos. Pessoas poderosas têm o potencial de exercer influência e o exercitam frequentemente. Por exemplo, um executivo poderoso pode influenciar um executivo de outra empresa a fazer negócios com a sua empresa. A autoridade é o direito formal para conseguir que as pessoas façam coisas ou o direito formal de controlar recursos. Os fatores internos da personalidade, como o talento ou o charme, podem ajudar a obter poder. Apenas a organização, no entanto, pode conceder a autoridade. Para compreender como os líderes usam o poder e a autoridade, examinamos os vários tipos de poder, táticas de influência, e como os líderes compartilham o poder com os membros da equipe. Compreender estas diferentes abordagens para o exercício da influência pode auxiliar um administrador a se tornar um líder eficaz.

Com o advento da globalização, as transformações do trabalho com o desafio da produtividade se tornaram ponto chave para o alcance dos resultados e de grandes transformações políticas, econômicas, sociais e tecnológicas. As organizações terão um maior desafio para conquistarem o sucesso, para isso deverão ser capazes de realizar a transformação de estratégias em ações, de enfrentar a incerteza, a ambiguidade, atuando com visão global, numa perspectiva de longo prazo, com capacidade de enfrentar riscos e transformar sua liderança em missões bem definidas e passíveis de serem cumpridas.

Essas transformações trouxeram impacto nas relações de liderança cujo enfoque é buscar o perfil ideal e desempenho compatível com a expectativa da função e do alcance de resultados por meio de metas específicas. O fator preponderante para se trabalhar em equipes e liderar de forma correta, está no crescimento pessoal e profissional, tanto do líder quanto do liderado. Portanto, a liderança busca identificar as necessidades de desenvolvimento do líder e do liderado, e estes, estando em uma equipe madura, inspiram os envolvidos a se comprometer e a estabelecer um plano de capacitação para melhoria de seus resultados.

O objetivo deste artigo é pesquisar o tema liderança nas organizações em uma amostra de 352 pessoas, através de um questionário composto por 12 perguntas com características quantitativas e qualitativas, para identificar os estilos de liderança interessantes para as organizações, as suas particularidades, perfis e forma de atuação. A importância do estudo justifica-se com os desafios de mercados globalizados e a concorrência atualmente competitiva, as organizações necessitam, cada vez mais, de líderes estrategistas, que possam traçar planos para o crescimento contínuo e vencer a concorrência. Não por acaso, esses líderes ocupam o primeiro lugar nos conselhos executivos de grandes corporações e engajam as pessoas para o crescimento pessoal e profissional.

As bases e fontes de poder são os meios controlados pelas unidades organizacionais e pelas pessoas nas organizações para obterem seu poder. As bases e fontes de poder podem vir de vários fatores, tais como a capacidade de recompensar ou coagir, a legitimidade, o conhecimento especializado, o acesso ao conhecimento, os laços de família e relações de amizade, cargo ou posição na estrutura, características pessoais, como o carisma, e por último a oportunidade de combinar e usar as fontes e bases de poder para influenciar a alocação de recursos da organização.

Outros fatores que devem ser analisados para entender o funcionamento do poder dizem respeito aos elementos que podem afetar a distribuição do poder nas organizações. O primeiro aspecto sobre a distribuição de poder é que a quantidade de poder total numa organização em qualquer momento é constante e que a sua distribuição varia ao longo do tempo, em função de um melhor acesso aos recursos tecnológicos, econômicos e humanos por alguma parte, sempre em detrimento do acesso por outra parte. Com exceção de momentos de crises profundas e acidentes, esta variação é lenta.

\section{Material e Métodos}

Para Michel (2009, p.53), "O método de pesquisa a ser utilizado será o que consiste na investigação de casos isolados ou de pequenos grupos, com o propósito básico de entender fatos, fenômenos sociais".

Observa-se que o tema do artigo sobre liderança tem como propósito identificar as relações da liderança nos ambientes organizacionais. As características diferenciadas estão na forma de trabalhar em equipe e conquistar os resultados através de pessoas e manter a sustentabilidade econômica, social e ambiental.

O método quantitativo está relacionado com dados em uma amostra que apresentam números. Bonat $(2009$, p.11) define que o método quantitativo é aquele que "vai aferir aquilo que pode ser mensurado, medido, contado. Possui, portanto, um alto teor descritivo". Dentro dessas características a pesquisa teve 352 participantes na sua maioria de nível superior e que mantém um cargo de liderança nas empresas.

Já o método qualitativo segundo Minayo (1998, p.81) "possibilita ao pesquisador a compreensão interpretativa ação 
social, o método qualitativo possibilitaria uma apreensão mais efetividade acerca das características e limites de cada ator social envolvido". No método qualitativo houve perguntas com manifestações da qualidade das informações com escalas de menor e maior importância para que as pessoas pudessem manifestar as suas opiniões de forma efetiva.

Neste artigo foi utilizado o método de pesquisa exploratória. Segundo Godoy et al (2006), para a realização de uma pesquisa de análise exploratória, é necessário um levantamento bibliográfico e também que seja realizada uma sequência de entrevistas com a pessoa que possui total conhecimento do problema de estudo da pesquisa.

O procedimento de coleta de dados é conceituado por Martins (2002, p.36) como sendo o levantamento feito junto “às fontes primárias, geralmente através de aplicação de questionários para grande quantidade de pessoas". Para Gil (2002) as pesquisas de levantamento caracterizam-se: pela interrogação direta das pessoas cujo comportamento se deseja conhecer.

O instrumento utilizado para efetivar a coleta de dados foi um questionário encaminhado de forma digital na mídia social Linkedin com um grupo de pessoas da cidade de CuritibaPR. Para Gil (2002), questionário é a técnica de investigação composta por um número mais ou menos elevado de questões apresentadas por escrito às pessoas, tendo como objetivo o conhecimento de opiniões, crenças, sentimentos, interesses, expectativas, situações vivenciadas.

Depois dos levantamentos de dados, relatou-se a análise dos resultados com a interpretação com base nas respostas extraídas do questionário e a conclusão do artigo.

\section{Resultados e Discussão}

A pesquisa foi realizada na cidade de Curitiba-PR, entre os meses de agosto e novembro de 2018, com 352 pessoas que trabalham em organizações de diversos segmentos. O enfoque da pesquisa foi analisar o perfil dos líderes nas organizações e a influência de estilos pertinentes para o gerenciamento eficaz com resultados satisfatórios. A maioria das pessoas foi do sexo masculino com $56,8 \%$ e o grau de instrução ensino superior 61,1\%, (Quadro 1).

Quadro 1 - Sexo e grau de instrução

\begin{tabular}{|c|c|c|c|}
\hline \multirow{2}{*}{ Sexo } & Masculino & 200 & $56,8 \%$ \\
\cline { 2 - 4 } & Feminino & 152 & $43,2 \%$ \\
\hline \multirow{3}{*}{ Grau de Instrução } & Ensino Médio & 20 & $5,7 \%$ \\
\cline { 2 - 4 } & Ensino Superior & 215 & $61,1 \%$ \\
\cline { 2 - 4 } & Pós-graduação & 93 & $26,4 \%$ \\
\cline { 2 - 4 } & Mestrado & 20 & $5,7 \%$ \\
\cline { 2 - 4 } & Doutorado & 4 & $1,10 \%$ \\
\hline
\end{tabular}

Fonte: Dados da pesquisa.

O percentual de $65,6 \%$ de pessoas já ocupou um cargo de liderança, diante do exposto, acredita-se que as experiências dos indivíduos terão uma forte representação no enfoque da pesquisa, devido a vivência no cotidiano das práticas de liderança. Como 57,4\% tem experiência no nível operacional, a visão poderá estar focada nas atividades operacionais, com a presença de normas e procedimentos para garantir a metodologia da política da qualidade, item de extrema relevância para a padronização de produtos e serviços.

Quadro 2 - Cargo de liderança em uma organização

\begin{tabular}{|l|c|c|c|}
\hline $\begin{array}{l}\text { 1 - Ocupa ou já ocupou um } \\
\text { cargo de liderança em uma } \\
\text { organização? }\end{array}$ & Sim & 231 & $65,6 \%$ \\
\cline { 2 - 4 } & Não & 121 & $34,4 \%$ \\
\hline \multirow{2}{*}{2 - Caso positivo, qual nível? } & Estratégico & 62 & $26,4 \%$ \\
\cline { 2 - 4 } & Tático & 38 & $16,2 \%$ \\
\cline { 2 - 4 } & Operacional & 135 & $57,4 \%$ \\
\hline
\end{tabular}

Fonte: Dados da pesquisa.

Apesar das bibliografias científicas não citarem o conceito de chefes e sim de liderança autoritária, 82,7\% analisa que há diferença. A questão não é somente conceitual, devido o chefe ter em suas características de autoridade o perfil de líder autoritário e fixar as suas diretrizes com metas factíveis e manifestar punições.

Quadro 3 - Diferença entre chefe e líder

\begin{tabular}{|l|l|c|c|}
\hline \multirow{4}{*}{$\begin{array}{l}\text { 3 - Há diferença } \\
\text { entre chefe e } \\
\text { líder? }\end{array}$} & $\begin{array}{l}\text { Não concordo totalmente } \\
\text { pão concordo } \\
\text { parcialmente }\end{array}$ & 10 & $2,8 \%$ \\
\cline { 2 - 4 } & Indiferente & 5 & $0,6 \%$ \\
\cline { 2 - 4 } & Concordo parcialmente & 44 & $12,4 \%$ \\
\cline { 2 - 4 } & Concordo totalmente & 291 & $82,7 \%$ \\
\hline
\end{tabular}

Fonte: Dados da pesquisa.

Observa-se que somente $15,3 \%$ dos entrevistados considera o chefe como líder, conforme mencionado na diferença entre o chefe e o líder, alguns autores da base científica não fazem menção da chefia, indicando a liderança autoritária como sendo a forma de chefe. Importante destacar que o conceito da liderança é a influência, explica-se o fato de algumas organizações manterem o estilo autoritário como forma de manter ordem e disciplina.

Quadro 4 - Chefe e líder

\begin{tabular}{|c|c|c|c|}
\hline \multirow{4}{*}{$\begin{array}{c}4 \text { - O chefe } \\
\text { também é um } \\
\text { líder? }\end{array}$} & Não concordo totalmente & 81 & $23 \%$ \\
\cline { 2 - 4 } & Não concordo parcialmente & 39 & $11,1 \%$ \\
\cline { 2 - 4 } & Indiferente & 8 & $2,3 \%$ \\
\cline { 2 - 4 } & Concordo parcialmente & 170 & $48,3 \%$ \\
\cline { 2 - 4 } & Concordo totalmente & 54 & $15,3 \%$ \\
\hline
\end{tabular}

Fonte: Dados da pesquisa.

A maioria dos entrevistados manifestaram a sua posição como concordo parcialmente $53,7 \%$, com a mudança da personalidade, apesar de autores da psicologia posicionarem que a personalidade advém das características genéticas, a visão dos entrevistados sobre a indagação pode ser explicada pelo fato da adaptação das pessoas devido mudanças drásticas que ocorrem nas organizações, no Brasil as mudanças são frequentes em virtude da instabilidade econômica e fatores políticos. 
Quadro 5 - Mudança de personalidade

\begin{tabular}{|c|c|c|c|}
\hline \multirow{3}{*}{$\begin{array}{c}\text { 5 - É possível } \\
\text { mudar a }\end{array}$} & Não concordo totalmente & 45 & $12,8 \%$ \\
\cline { 2 - 4 } $\begin{array}{c}\text { personalidade } \\
\text { em virtude da }\end{array}$ & Não concordo parcialmente & 25 & $7,1 \%$ \\
\cline { 2 - 4 } & Indiferente & 2 & $0,6 \%$ \\
\cline { 2 - 4 } liderança? & Concordo parcialmente & 189 & $53,7 \%$ \\
\cline { 2 - 4 } & Concordo totalmente & 91 & $25,9 \%$ \\
\hline
\end{tabular}

Fonte: Dados da pesquisa.

A maioria dos entrevistados concordam parcialmente que a posição social interfere na liderança, diante da expressão, observa-se que as histórias de sucesso de empresários, atletas, escritores, entre outros, criam influências nas pessoas para seguir os passos dos líderes de sucesso e as mídias tem um grande papel na divulgação.

Quadro 6 - Posição social e liderança

\begin{tabular}{|c|c|c|c|}
\hline \multirow{5}{*}{$\begin{array}{l}\text { 6- A posição } \\
\text { social interfere } \\
\text { na liderança? }\end{array}$} & Não concordo totalmente & 74 & $21 \%$ \\
\hline & $\begin{array}{l}\text { Não concordo } \\
\text { parcialmente }\end{array}$ & 35 & $9,9 \%$ \\
\hline & Indiferente & 44 & $12,5 \%$ \\
\hline & Concordo parcialmente & 143 & $40,6 \%$ \\
\hline & Concordo totalmente & 56 & $15,9 \%$ \\
\hline
\end{tabular}

Fonte: Dados da pesquisa.

Para os entrevistados as opções concordo parcialmente e concordo totalmente soma-se um total de $65,6 \%$, indicando que as possibilidades de diferenças são expressivas, isto se deve a fatores culturais e maneiras de exercer a liderança no ambiente organizacional.

Quadro 7 - Diferença entre liderança - sexo feminino e masculino

\begin{tabular}{|c|c|c|c|}
\hline \multirow{2}{*}{$\begin{array}{c}\text { 7- Há } \\
\text { diferenças entre }\end{array}$} & Não concordo totalmente & 59 & $16,8 \%$ \\
\cline { 2 - 4 } $\begin{array}{c}\text { a liderança das } \\
\text { pessoas do sexo } \\
\text { masculino e } \\
\text { feminino? }\end{array}$ & $\begin{array}{c}\text { Não concordo } \\
\text { parcialmente }\end{array}$ & 15 & $4,3 \%$ \\
\cline { 2 - 4 } & Indiferente & 47 & $13,4 \%$ \\
\cline { 2 - 4 } & Concordo parcialmente & 142 & $40,3 \%$ \\
\hline
\end{tabular}

Fonte: Dados da pesquisa.

Devido os entrevistados estarem desempenhando atividades nas organizações entradas em resultados, observase que a maioria menciona que a liderança deve buscar resultados favoráveis - concordo parcialmente 45,2\% e concordo totalmente $31,8 \%$, porém alguns líderes podem ter outras posições para os resultados, como por exemplo o líder comunitário que estabelece um apelo social onde o resultado com a premissa de proporcionar o bem-estar das pessoas. As organizações por mais que propiciem a qualidade de vida, necessita remunerar o empresário ou os acionistas, para continuar a atividade.
Quadro 8 - Liderança e resultados

\begin{tabular}{|c|c|c|c|}
\hline \multirow{5}{*}{$\begin{array}{l}\text { 8- A liderança } \\
\text { nas organizações } \\
\text { deverá estar } \\
\text { centrada nos } \\
\text { resultados } \\
\text { favoráveis? }\end{array}$} & Não concordo totalmente & 27 & $7,7 \%$ \\
\hline & Não concordo parcialmente & 42 & $11,9 \%$ \\
\hline & Indiferente & 12 & $3,4 \%$ \\
\hline & Concordo parcialmente & 159 & $45,2 \%$ \\
\hline & Concordo totalmente & 112 & $31,8 \%$ \\
\hline
\end{tabular}

Fonte: Dados da pesquisa.

Observa-se que a maioria dos entrevistados se consideram democráticos $41,2 \%$, apesar de destacarem que a organização necessita estar focada em resultados, outro fator que chama a atenção é que poucos entrevistados se consideram autocrático $3,1 \%$, verifica-se que os entrevistados não avaliam o líder autocrático como benéfico para a organização e 8,5\% não sabem responder, diante deste percentual de dúvida, significa que o tema da liderança deve ser debatido e explorado nas organizações e na educação continuada.

Quadro 9 - Estilo de liderança

\begin{tabular}{|c|c|c|c|}
\hline \multirow{4}{*}{\begin{tabular}{c} 
9 - Qual o \\
seu estilo de \\
\cline { 2 - 4 }
\end{tabular}} & Autocrático & 11 & $3,1 \%$ \\
\cline { 2 - 4 } & Democrático & 145 & $41,2 \%$ \\
\cline { 2 - 4 } & Liberal & 14 & $4 \%$ \\
\cline { 2 - 4 } & Carismático & 64 & $18,2 \%$ \\
\cline { 2 - 4 } & Situacional & 88 & $25 \%$ \\
\cline { 2 - 4 } & Não sei responder & 30 & $8,5 \%$ \\
\hline
\end{tabular}

Fonte: Dados da pesquisa.

De acordo com os entrevistados o estilo mais utilizado nas organizações é o autocrático $56,3 \%$, essa afirmação assemelhase com a resposta da liderança focada em resultados, porém descreve um contraste com o perfil de liderança da maioria dos entrevistados que se consideram democráticos que nesta pergunta obteve 11,6\%. A liderança liberal não foi escolhida, observa-se que muitos ainda têm preconceito com o liberal, pois pode significar um alto grau de flexibilidade sem normas e procedimentos, como a maioria dos líderes são da base operacional, o estilo não possui muito significado. A liderança situacional teve $21,9 \%$, conforme mencionado na pergunta 5 sobre a mudança de personalidade as mudanças de cunho político e econômico no Brasil são frequentes.

Quadro 10 - Estilo de liderança utilizado nas organizações

\begin{tabular}{|c|c|c|c|}
\hline \multirow{2}{*}{$\begin{array}{c}\text { 10 -Na sua } \\
\text { opinião, qual } \\
\text { estilo de }\end{array}$} & Autocrático & 198 & $56,3 \%$ \\
\cline { 2 - 4 } liderança mais & Democrático & 41 & $11,6 \%$ \\
\cline { 2 - 4 } & Liberal & 0 & - \\
\cline { 2 - 4 } utilizado nas \\
\cline { 2 - 4 } organizações? & Carismático & 9 & $2,6 \%$ \\
\cline { 2 - 4 } & Situacional & 77 & $21,9 \%$ \\
\hline
\end{tabular}

Fonte: Dados da pesquisa.

\section{Conclusão}

Dentro da temática do artigo estabelece que o assunto apesar de conhecido e debatido no Brasil, com uma vasta literatura científica, merece ser estudado e avaliado, diante das dúvidas e análises com divergências. O significado da liderança no ambiente organizacional é complexo pois há 
muitas divergências de opiniões, criando posicionamentos antagônicos como constatado na pesquisa com relação ao perfil utilizado nas organizações como autocrático, porém a grande parte dos líderes, consideram-se democráticos, a explicação pode ser dada pelo fato do perfil negativo do chefe e a sua ligação com a visão autocrática.

Diante da divulgação por meio da mídia e livros, alguns perfis de liderança são colocados como obsoletos e não desejáveis, porém, a liderança depende do ambiente organizacional, portanto é o ambiente que promoverá o perfil de liderança adequado, dentro do estudo do artigo observa-se que a liderança pautada nos resultados tem maior aderência e o perfil autocrático é o mais visto nas empresas.

A liderança é uma forma de influência, por isso não se pode estabelecer e mencionar o melhor estilo, por mais que a literatura estabeleça uma tendência para perfis com maiores flexibilidades de diálogos, espírito de equipe, o perfil de normas, leis e procedimentos pautados nas prerrogativas do estilo autocrático ainda é muito usado nas organizações. É fato que as organizações necessitam de capital financeiro para remunerar os empresários e acionistas, portanto a liderança mais eficiente para conquistar resultados será estabelecida, na atualidade os novos negócios estão centrados em uma liderança inspiradora, com remuneração variável nas conquistas empresariais com base em ideias inovadoras, assim um perfil autocrático com aplicação de normas, leis e procedimentos podem não ter a mesma eficiência como em uma empresa tradicional.

\section{Referências}

BONAT, D. Metodologia da pesquisa. Curitiba: IESDE, 2009.

GIL, A.C. Como elaborar projetos de pesquisa. São Paulo: Atlas, 2002.

GODOY, C.K; MELO R.B; SILVA, A.B. Pesquisa qualitativa em estudos organizacionais: paradigmas, estratégias e métodos. São Paulo: Saraiva, 2006.

MARTINS, G.A. Manual para elaboração de monografias e dissertações. São Paulo: Atlas, 2002.

MICHEL, M.H. Metodologia e pesquisa cientifica em ciências sociais: um guia prático para acompanhamento da disciplina e elaboração de trabalhos monográficos. São Paulo: Atlas, 2009.

MINAYO, M.C.S. O desafio do conhecimento. Pesquisa qualitativa em saúde. São Paulo: Hucitec, 1998.

MOSCOVICI, F. Desenvolvimento interpessoal: treinamento em grupo. Rio de Janeiro: José Olympio, 2013.

RIBEIRO, A.L. Teorias da administração. São Paulo: Saraiva, 2010.

ROBBINS, S.; JUDGE, T. Fundamentos do comportamento organizacional. São Paulo: Pearson Education do Brasil, 2014. 